\title{
Physically-based Finite Element Strength Prediction in Notched Woven Laminates under Quasi-static Loading
}

\author{
H. Ahmad ${ }^{1}$, A D Crocombe ${ }^{2}$, and P A Smith ${ }^{2}$ \\ ${ }^{1}$ Department of Structures and Materials Engineering, \\ Faculty of Civil and Environmental Engineering, \\ Universiti Tun Hussein Onn Malaysia, \\ 86400 Parit Raja, Batu Pahat, \\ Johor Darul Tak'zim, MALAYSIA. \\ ${ }^{2}$ Division of Mechanical, Medical and Aerospace Engineering, \\ Faculty of Engineering and Physical Sciences, \\ University of Surrey, Guildford, \\ Surrey, GU2 7XH, \\ UNITED KINGDOM.
}

\begin{abstract}
The present paper is concerned with modelling damage and fracture in notched woven fabric composites. Previous experimental work has shown that, under tensile loading, damage at a notch in a variety of GFRP and CFRP composites based on woven fabric reinforcement comprises matrix damage and fibre tow fracture along the plane of maximum stress. It is these experimental observations that inform the failure modelling developed here, in which a cohesive zone approach is used within a two-dimensional extended finite element method (XFEM) framework. The traction-separation parameters used in the XFEM implementation are based on previously reported experimental measurements for the strength and toughness of the woven fabric materials under investigation. The approach is shown to provide predictions of notched strength that are in very good agreement with experimental results from the literature for a range of GFRP and CFRP woven fabric systems and also agree well with results obtained from closed-form analytical models, which require calibration.
\end{abstract}

Keywords - Circular Hole, Notched Plate, Strength Prediction, Stress, Woven Composite, XFEM,

\section{Introduction}

Woven fabric based composite materials are an attractive option for a range of engineering applications. Although the mechanical properties are not as good as those of their non-woven 
counterparts, they still offer reasonable specific stiffness and strength with particularly good impact and energy absorption characteristics. Moreover they offer some economies and greater flexibility in processing options. A particular problem with woven composites (as with other composites) is their sensitivity to the presence of stress concentrations, such as those provided by an open hole and bolted joint. Unlike many structural metallic materials, composite materials in general lack the capability to deform plastically in the macroscopic sense and this means that failure at a stress raiser in a composite occurs in a relatively brittle fashion. Notwithstanding this, composite materials have the capability to sustain damage prior to fracture; this means that the notched strength is greater than would be expected simply on the basis of the elastic stress concentration factor. The damage mechanisms in notched woven composite plates differ from those in notched non-woven composite plate and this has implications for the modelling approach.

The failure of composite materials from a stress raiser, particularly an open hole, has been researched extensively over the years. Early closed-form models (of which the most well-known are perhaps the point and average stress criteria of Whitney and Nuismer, [1]) have been followed by finite element based approaches of varying degrees of complexity. Some of the latter models treat the composite as a homogeneous material for the purpose of the stress analysis and then use laminate theory and two-dimensional in-plane failure models to simulate progressive damage at the ply level, followed by a degradation of the elastic properties to account for the stress redistribution before ultimate failure e.g. Chang and Chang [2]. Other models use a quasi-two dimensional approach, Kortshot et. al. [3], or a full three dimensional analysis, e.g. Hallet et. al. [4]. These approaches represent the observed damage more realistically - in particular they incorporate through-thickness damage (delamination) in addition to in-plane damage. Kortshot et. al. [3] proposed a model for notched strength prediction which represents the effect of intra-ply damage (local unidirectional ply splitting) and inter-ply (associated delamination) cracking on the stress distribution near the notch tip in the longitudinal plies of notched cross-ply laminates and uses a statistical Weibull-based failure criterion in 2D model to predict the failure of the $0^{\circ}$ plies and hence the notched strength. Hallet et. al. [4] modelled damage within a FE framework and used the approach to investigate the effect of a number of parameters (hole diameter, ply thickness and laminate thickness) on the strength of notched quasi-isotropic CFRP laminates subjected to tensile stress. Another class of failure model (discussed further below) is based on modelling macroscopic through-thickness crack growth from the notch, an approach which is perhaps not consistent with the observed failure mechanism in laminates based on unidirectional layers of reinforcement such as discussed above. 
Many of the more widely-used approaches to predict notched strength are semi-empirical in nature and this limits their general applicability. In particular the sub-critical damage that develops at notches (and which needs to be represented in some way within any model) varies according to the details of the composite under investigation. Hence it is only through the use of physically based models that there is the possibility of a failure theory being applicable to more than one class of problem without extensive recalibration of the model. In a notched woven fabric GFRP composite subjected to tension, it has been shown experimentally using a model (transparent) GFRP system that prior to failure an intense zone of damage develops in the region of maximum tensile stress (Belmonte et. al [5]). Damage within that zone comprises matrix cracking and splitting, but also fibre tow fracture. In that sense the damage resembles stable self-similar crack growth, suggesting that a fracture mechanics-based model is a physically reasonable one to use. A similar study was carried by Belmonte et al. [6] on woven quasi-isotropic and cross-ply CFRP. Although the opaque nature of the CFRP means that direct observations of damage are less straightforward, there was evidence of tow failure before specimen failure. Other valuable data concerning notched tensile strength of woven composites had been presented previously by Kim et al., [7]. More recent work by Zahari et al [8] has considered the notched compressive behaviour of woven GFRP.

The previous paragraph suggests that an appropriate failure model for notched woven fabric composites under tensile loading would consider the damage growth from the notch explicitly. There are a number of essentially similar techniques that treat the problem in this way. A particular stress-displacement relation is assumed within the damage zone and the energy absorbed in separating the crack faces corresponds to the material toughness, $\mathrm{G}_{\mathrm{c}}$. One of the first models to adopt this method was that of Eriksson and Aronsson [9] who assumed a constant cohesive stress-displacement relationship within the damage zone. An approximate analytical version of this approach, a "critical damage growth" (CDG) model, was presented by Hitchen et. al [10], building on earlier work by Soutis and Fleck [11], and this was applied subsequently to woven composites [5,6]. Afaghi-Khatibi et. al. [12] presented an "equivalent crack growth model" (ECGM) which assumed a linear decrease of cohesive stress with displacement in the damage zone, which they applied successfully to the data of Kim et al. [7].

The present work explores further the applicability of this type of approach, which in the present paper is incorporated within an extended finite element (XFEM) formulation. A limitation of the previous studies is that the material parameters within the models have generally been calibrated against experimental data rather than determined independently. Here we use independent measurements of unnotched strength and toughness, where available, to develop numerical models for the experimental studies on woven fabric systems conducted by Kim et. al. using GFRP [7] and 
Belmonte et al. using GFRP [5] and CFRP [6]. In the next section details of the numerical procedure are provided. XFEM predictions are compared with experiment and other closed-form solutions in subsequent sections.

\section{Finite Element Modelling}

\subsection{Notched Plate Geometry and Material Properties}

The three experimental studies from the literature were modelled within a two - dimensional finite element framework using ABAQUS CAE Version 6.9.1 [15]. For all the models, the plate symmetry means that only half of the coupon needed to be modelled, Figure 1, reducing computational cost and time during the processing stage. The first data set is taken from the extensive experimental work conducted by Kim et al. [7] using three types of woven fabric composite systems with various combinations of notch sizes, laminate width and volume fraction. All plates have a length (L) of 200 $\mathrm{mm}$ with varying widths (W) and a circular hole of diameter (d) $5 \mathrm{~mm}$. Table 1 shows the geometry and material properties for all the woven fabric systems investigated experimentally by Kim et al. [7] that are being modelled in current paper. The elastic properties are required for the stress analysis while to implement the damage model the unnotched strength, $\sigma_{o}$ and the fracture energy, $G_{c}$ are also required. Independently measured values for the latter were not reported by Kim et $a l$.[7]. Instead they derived their values from an analysis of the notched strength experimental data and this is the origin of the notch size dependent data (strength and fracture energy) seen in Table 1, apparent in the glass-epoxy in particular. In the absence of independently measured properties, these fracture energy values are used in the current work as it enables comparison not only with the experimental data from [7] but also with the ECGM approach, which has been applied to the same data set [12].

The second and third data sets were taken from the work of Belmonte et al. for woven GFRP laminates [5] and woven CFRP laminates [6] respectively. The plates were $130 \mathrm{~mm}$ gauge length (GFRP) or $150 \mathrm{~mm}$ gauge length (CFRP) and constant width of $25 \mathrm{~mm}$ with notch sizes (hole diameters), $d$, of 2.5, 5.0 and $10.0 \mathrm{~mm}$ giving $d / W$ ratios of $0.1,0.2$ and 0.4 respectively. Belmonte also included an additional series of larger CFRP specimens from the thickest plates that were of gauge length $380 \mathrm{~mm}$, width $120 \mathrm{~mm}$ and contained a $20 \mathrm{~mm}$ diameter hole corresponding to $d / W=$ 0.17. Belmonte et al. [5,6] carried out experiments on two different types of woven composite systems, i.e., GFRP and CFRP. The material properties are shown in Tables 2 and 3. The GFRP systems comprised two stacking sequences of a four-layer quasi-isotropic composite [Table 2]. The 
woven CFRP systems investigated were of two types (a plain weave and a five harness satin weave, two different lay-ups (cross-ply and quasi-isotropic) and three different plate thickness for each giving 12 systems in total [Table 3]. In contrast with Kim et al. [7], Belmonte et al. [5, 6] reported values of fracture energy that were measured independently for each lay-up using a single-edge-notch fracture mechanics specimens in accordance with ASTM E 399-90.

\subsection{Implementation of Constitutive Law in FE Modelling}

A typical plane stress mesh used in the FE modelling is shown in Figure 2. The meshes are refined in the vicinity of notch edge, while away from the notch the mesh can be made coarser. Mesh refinement was investigated and is discussed in a later section (3.1). As indicated earlier, in the notched plate under increasing tensile load, damage is assumed to grow in a self-similar manner along the plane of net tension (reduced area). Hence only crack opening (mode 1) needs to be considered. In this work, two methods for modelling the damage have been used, namely XFEM and cohesive zone modelling (CZM). All of the data was modelled using XFEM and some of Belmonte et al.'s [5,6] data was also modelled using CZM. Both methods use the same traction separation damage model, illustrated schematically in Figure 3. This material model behaves in a linear manner until the traction reaches a critical value (strength parameter) and then unloads with increasing displacement dissipating the fracture energy $\left(G_{c}\right)$ in the process. The strength parameter has been taken as the un-notched strength $\left(\sigma_{o}\right)$ of the laminate. The values of strength parameter (unnotched strength, $\sigma_{o}$ ) and fracture toughness, $G_{c}$ are obtained from literature [Afaghi-Khatibi et al. [12]] and independently from experimental work [Belmonte et al. [5,6]] and are shown in Tables 1-3. Both damage models have been embedded within a mesh of $2 \mathrm{D}$ continuum elements having a linear elastic plane stress response. Both damage models are discussed briefly below.

In conventional FE modeling a discontinuity such as crack requires accurate modeling and hence mesh refinement. Further, crack propagation usually requires a pre-defined crack path allowing the propagation of cracks along element boundaries. XFEM, which is an extension to conventional FE methods, is based on an enrichment function that allows a displacement jump between crack faces to occur during crack propagation. Crack path and crack location are not required to be specified a priori and the elements effectively split to allow arbitrary crack propagation. The response at this split is defined by the traction-separation response discussed above.

Damage initiation and propagation is simulated at regions experiencing principal stresses greater than corresponding values specified in traction-separation law and always take place orthogonally to the maximum principal stresses. Damage initiation is triggered when the maximum principal stress reaches the critical traction. Damage evolution is controlled by a damage parameter (D) 
which is determined from the current separation and the release separation (determined from $G_{c}$ and $\sigma_{o}$ ) Fracture makes the structural response non-linear and numerical methods can experience difficulty converging to a solution. Viscous regularization (a form of damping) has been used to facilitate convergence and a parametric study was undertaken to determine the optimum value (small enough not to influence the solution values but large enough to allow convergence to be obtained) The XFEM region (i.e. the region capable of sustaining damage) was assigned to a band of the model adjacent to the notch edge (see Figure 2). Four-noded two-dimensional plane stress elements (CPS4) were used as the current implementation of XFEM only worked in conjunction with $1^{\text {st }}$ order elements.

Unlike XFEM, cohesive zone modelling (CZM) requires that the failure path is specified beforehand and seeded with cohesive elements [13]. As already discussed, the method of modelling the damage in the CZM is the same as in the XFEM approach (a traction-separation response). The cohesive zone elements were located along the net-section plane. The elements are required to be thin $(0.01 \mathrm{~mm}$ was used in the current work) and were assigned a high initial stiffness. Cohesive elements (COH2D4) were used within cohesive zone region and 8-noded quadratic plane stress elements (CPS8) were used in un-cracked region. Along common interfaces the elements were connected using a tie constraint.

\section{Comparison of Strength Prediction with Experimental Data and Other Models.}

\subsection{Woven Composite systems tested by Kim et al. [7]}

Comparison between XFEM results and experimental data for the notched woven laminates reported by Kim et al. [7] are shown in Figure 4. In general the agreement is good with discrepancies no more than $20 \%$ (and generally much less than this) for any system/notch size. In all cases apart from the $30 \mathrm{~mm}$ wide glass polyester samples, the XFEM approach underestimates the experimental strength. A slightly larger error overall is observed for the glass-polyester composites than the other systems, but no particular significance is attached to this, especially given the uncertainty regarding the toughness values. Figure 5 compares the XFEM results to ECGM approach adopted by Afaghi-Khatibi et al. [12]. The agreement between the ECGM results and XFEM is very good, not unexpectedly as both represent fracture mechanics formulations of the problem, and this provides validation for the XFEM formulation used here.

Typical load-displacement plots from the XFEM modelling are shown in Figure 6, giving results from $10 \mathrm{~mm}$ wide glass/epoxy lay-up plates with hole diameter of $0.4 \mathrm{~mm}$ and close-up view damage plots at specific locations in the graph were illustrated in Figure 7. Due to large stress 
concentration at the vicinity of hole as tension load is applied, the onset of damage will be initiated at the hole edge as expected. After initiation, the crack was still able to carry increased load until it reached about one hole diameter in length which point ultimate failure occurred. It would appear that the length of the process zone is critical in determining ultimate failure. This process continued until the plate separated completely associated with catastrophic failure after maximum load been achieved. Two types of parametric studies were carried out to determine the sensitivity of the strength prediction to key model parameters $(10 \mathrm{~mm}$ wide glass/epoxy with $0.4 \mathrm{~mm}$ hole diameter was chosen for this purpose). The first study was to determine an acceptable viscous regularisation value to use to ensure the strength prediction results were independence from the viscosity constant. It was found that it was difficult to obtain converged solutions if the viscosity was too small, however, as can be seen, large viscosity values gave excessive and non-physical results. From Figure 8 , a viscosity of 0.0001 is sufficient as lower values produce similar results. The second study assessed mesh sensitivity and the results are shown in Figure 9. The number of elements refers to the region surrounding the hole, the mesh surrounding the hole was refined in a radial direction. It can be seen that there is no significant mesh sensitivity; indeed one of the basic features of XFEM formulation is that a high level of mesh refinement at the crack tip is not required [14].

\subsection{Quasi-isotropic Woven GFRP tested by Belmonte et al. [5]}

As expected, all of the models showed failure along the net-tension plane, which is within the enriched XFEM region specified in the model. The XFEM predicted notched strengths are compared with experimental data, CZM predictions and various analytical approaches [5] in Figure 10. Typical load-displacement plot is given in Figure 11, with associated enclosed view at crack initiation and propagation point displayed in Figure 12. Similar fashion of XFEM results of load-displacement plot was observed as shown in earlier case (Figure 6). The XFEM gives very reasonable agreement with experimental data, to within less than $6 \%$ and with the CZM. Minor discrepancies between the XFEM and CZM are most likely due to the different element types (the elements used in CZM were quadratic while in XFEM only a linear elements could be used as suggested in the relevant ABAQUS manual [14]). For the $(0 / 90 /+45 /-45)_{\mathrm{s}}$ lay-up the Whitney-Nuismer point and average stress criterion (PSC and ASC), give excellent agreement as expected (these semi-empirical models are calibrated at one of the notched strength results). The CDG model also gives good agreement. The strength predictions for the $(90 / 0 /+45 /-45)_{\mathrm{s}}$ are reasonable. Note that for this stacking sequence, the same strength and toughness values were assigned as for the other stacking sequence. The results perhaps suggest that this stacking sequence has a lower strength and/or toughness - a lower toughness would be consistent with the surface $90^{\circ}$ layers restricting the extent of $0^{\circ}$ ply splitting, which seems plausible. 


\subsection{Cross-ply and Quasi-isotropic woven CFRP tested by Belmonte et al. [6]}

The results for the cross-ply and quasi isotropic woven CFRP composite systems with different notch sizes are presented in a similar way in Figure 13. Both CZM and XFEM modelling of failure initiation and propagation in woven CFRP exhibited similar trends as shown in woven GFRP. Overall agreement is very good, within 10\% for most systems (the range of error is $0.09 \%$ $19.41 \%)$. Similar size errors were found in large width $(40 \mathrm{~mm})$ and small width $(25 \mathrm{~mm})$ specimens. In almost all cases the XFEM tends to underestimate the experimental strength, with a higher discrepancy for the cross-ply systems than the quasi-isotropic systems. The underestimation may be a result of the simplifying assumptions within the constitutive law. For instance the tow fractures tend to follow the crimp regions and this means that the assumption of self-similar crack growth is not entirely realistic.

As with the GFRP results, the PSC and ASC (the Whitney-Nuismer failure criteria) give the best predictions compared to other approaches for the hole sizes of $10 \mathrm{~mm}$ or less, over which range they were calibrated against the experimental data. As a result the PSC and ASC predictions are less good for the larger hole size of $20 \mathrm{~mm}$ where the same characteristic distance values were used. Overall the numerical results obtained here using XFEM show better prediction than the critical damage growth (CDG) model implemented by Belmonte et. al [6], especially for the cross-ply systems. The CDG model was formulated based on an isotropic analysis, which could only be corrected partially for the orthotropic cross-ply systems and so the discrepancies are perhaps not surprising.

\section{Concluding Remarks}

2-D modelling of notched woven GFRP and CFRP composites plates has been implemented within an FE framework. XFEM and CZM approaches gave very reasonable agreement with the experimental data for all the systems investigated. There was also good agreement with a range of other modelling approaches. The advantages of the XFEM/CZM approach used in the present work are that, unlike the other approaches, it is physically based (and consistent with experimental observations of damage and fracture) and that it may be implemented using independently measured material properties. In turn this offers the prospect that the approach may be applicable to failure in other classes of problem (e.g., net-tension failure at a bolted joint) without extensive recalibration of the model. 


\section{References}

[1]. Whitney, J.M., Nuismer, R.J.," Stress fracture criteria for laminated composites containing stress concentrations.” Journal of Composite Materials, Vol. 8 pp 253-265, 1974

[2]. Chang, F.K., Chang, K.Y.,. "A progressive damage model for laminated composites containing stress concentrations." Journal of Composite Materials ,Vol. 21(3), pp 834-855, 1987

[3]. Kortschot, M.T., Beaumont, P.W.R., Ashby, M.F., "Damage mechanics of composite materials: III - Prediction of damage growth and notched strength." Composite Science and Technology Vol. 40, pp 147-165, 1991

[4]. Hallett, S.R., Green, B.G., Jiang, W.G., Wisnom, M.R.,. "An experimental and numerical investigation into the damage mechanisms in notched composites." Composite Part A, Vol. 40, pp 613-624, 2009

[5]. Belmonte, H.M.S., Manger, C.I.C., Ogin, S.L., Smith, P.A., Lewin, R., " Characterisation and modeling of the notched tensile fracture of woven quasi-isotropic GFRP laminates." Composites Science and Technology, Vol. 61 pp 585-597, 2001

[6]. Belmonte, H.M.S., Ogin, S.L., Smith, P.A., Lewin, R., “ A physically-based model for the notched strength of woven quasi-isotropic CFRP laminates. ." Composites Part A, Vol. 35, pp 763-778, 2004

[7]. Kim, J.K., Kim, D.S., Takeda, N., "Notched Strength and Fracture Criterion in Fabric Composite Plates Containing a Circular Hole.” Journal Composite Materials, Vol. 29, part 7 pp. 982-998, 1995

[8]. Zahari, R., Azmee, A.H., Mustapha, F., Salit, M.S., Varatharajoo, R., Shakrine, "Prediction of Progressive failure in Woven Glass/Epoxy Composite Laminated Panels”, Journal Mekanikal, Vol. 25, pp. 80-91, 2008.

[9]. Eriksson, I., Aronsson, C.G.,. "Strength of Tensile Loaded Graphite/Epoxy Laminates Containg Crack, Open and Filled Holes.” Journal of Composite Materials, Vol. 24, pp. 456-482, 1990.

[10]. Hitchen, S.A., Ogin, S.L., Smith, P.A., Soutis, C., "The Effect of Fibre Length on Fracture Toughness and Notchness and Notched Strength of Short Carbon Fibre/Epoxy Composites." Composites, Vol. 6 pp 407-413, 1994

[11]. Soutis, C., Fleck N.A.,. "Static compression failure of carbon fibre T800/924C composite plate with a single hole." Journal Composite Materials, 1990: 24:536-558

[12]. Afaghi-Khatibi, A., Ye, L., and Ma, Y.W., "An effective crack growth model for residual strength evaluation of composite laminates with circular holes.” Journal Composite Materials, Vol. 30, pp 142-163, 1996

[13]. H. Ahmad, A.D. Crocombe, P.A. Smith, "Strength Prediction of Notched Woven Composite Plates using Cohesive Zone Approach." 2011 SIMULIA Customer Conference, Barcelona, Spain, 2011.

[14]. 6.9.1, ABAQUS®V. User's Manual and Theory Manual. Hibbit, Karlson and Sorensen, Inc. 


\section{Figures}

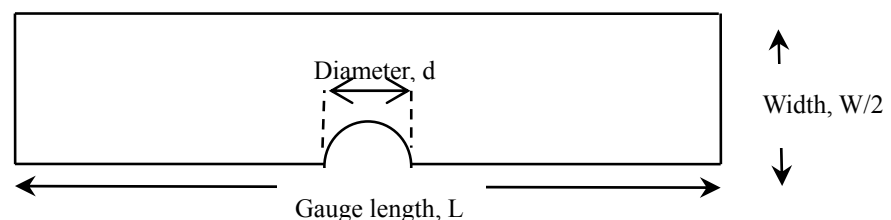

Fig. 1. Geometry of notched composite plate model, used for all experimental cases

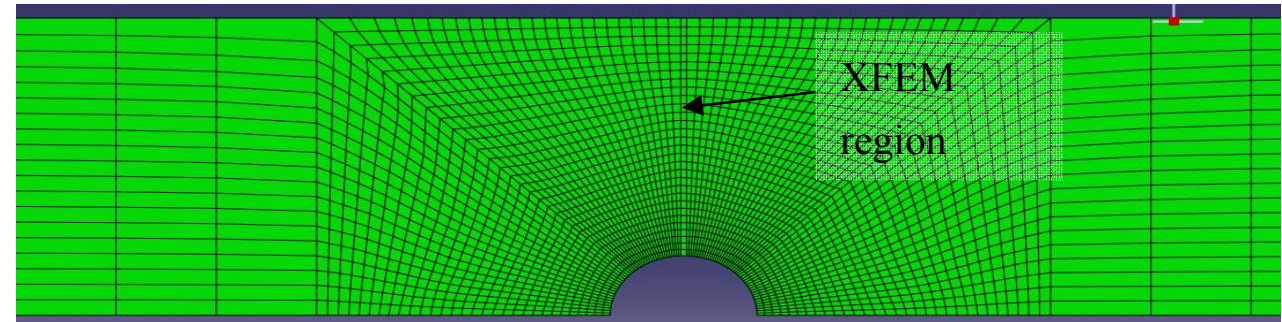

Fig. 2: Mesh of the model implemented

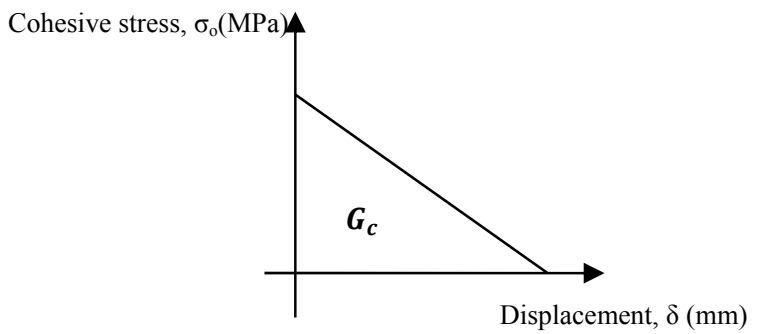

Fig. 3. Physically-based constitutive model used in the current analysis
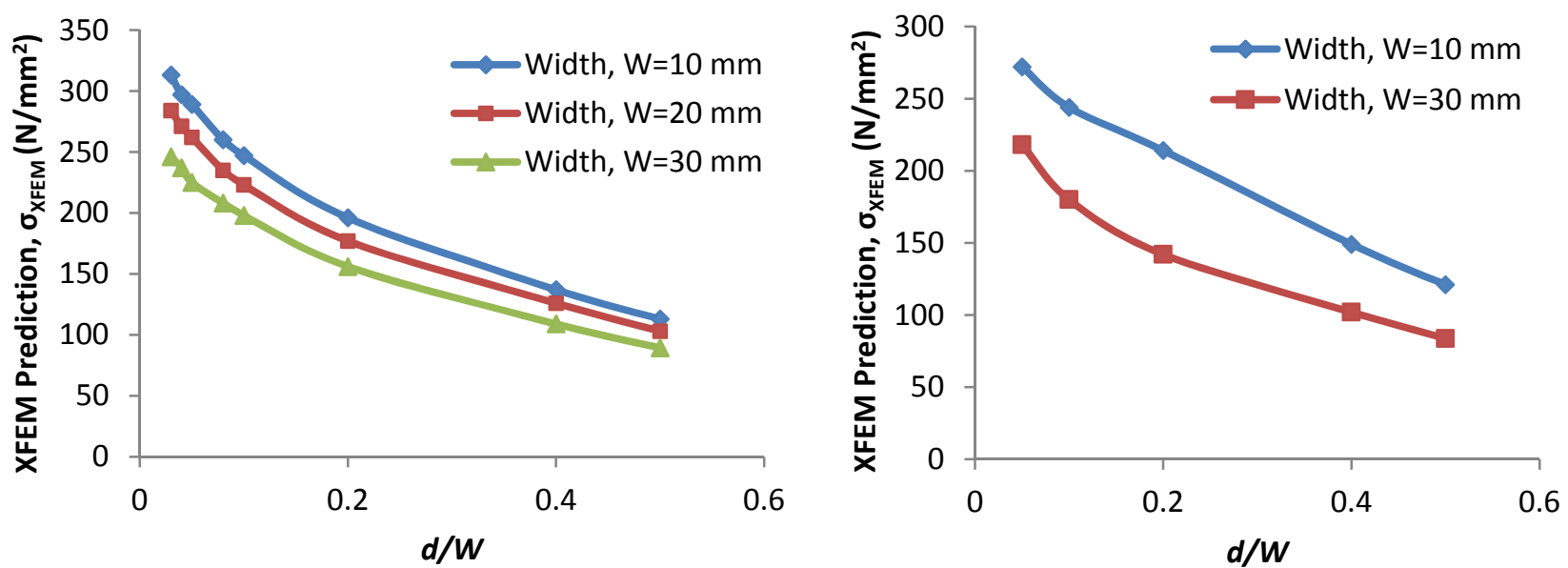
(a) Glass-Epoxy

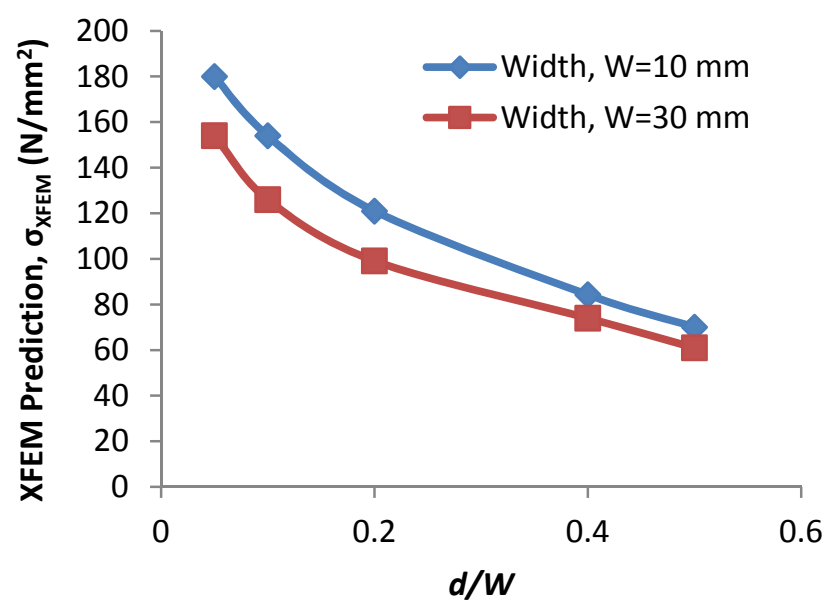

(c) Glass-polyester $\left(\mathrm{V}_{1 \mathrm{f}}=44.5 \%\right)$ (b) Glass-polyester $\left(\mathrm{V}_{1 \mathrm{f}}=60 \%\right)$

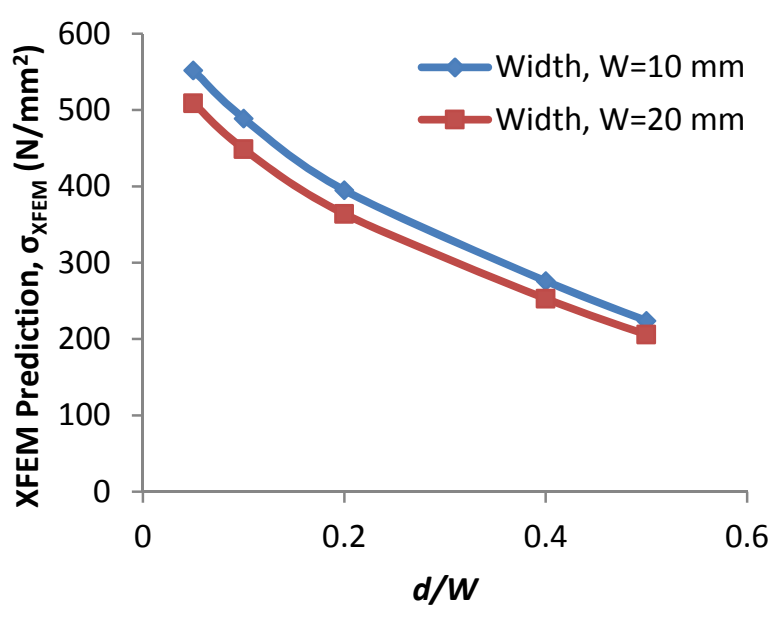

(d) Carbon-Epoxy

Fig. 4. Comparison of experimental notched strength with XFEM modelling of Kim et al.'s work [7]

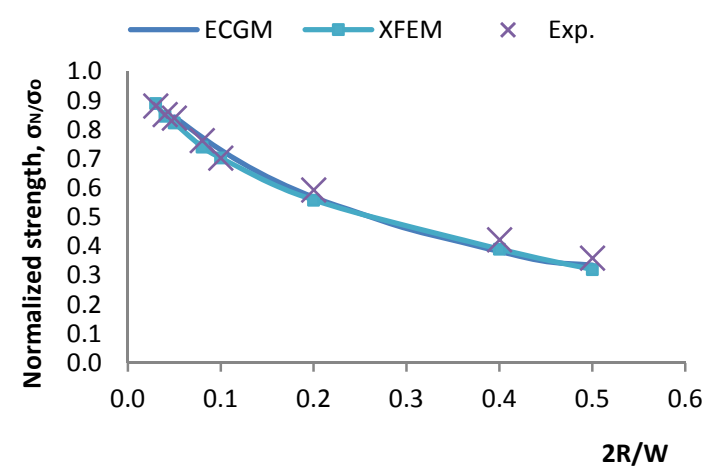

(a) Glass-Epoxy, $\mathrm{W}=10 \mathrm{~mm}$

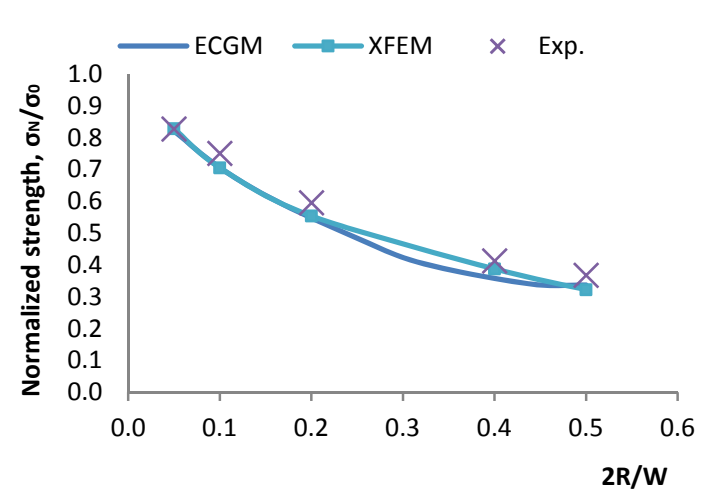

(c) Glass-polyester, $\mathrm{W}=30 \mathrm{~mm}, \mathrm{v}_{\mathrm{f}}=44.5 \%$

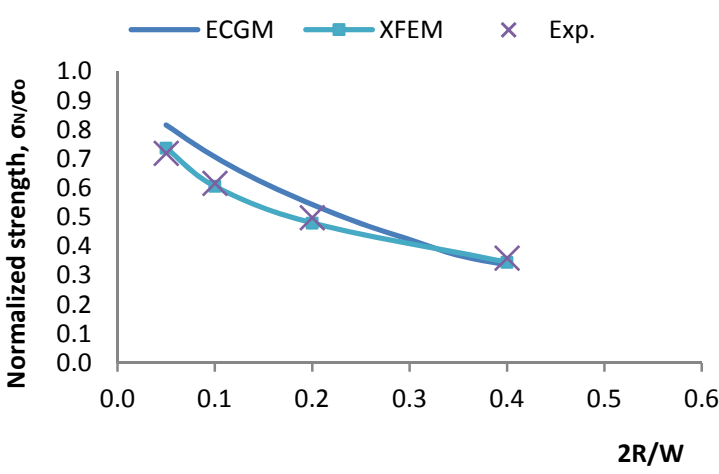

(b) Glass-polyester, $\mathrm{W}=30 \mathrm{~mm}, \mathrm{v}_{\mathrm{f}}=60 \%$

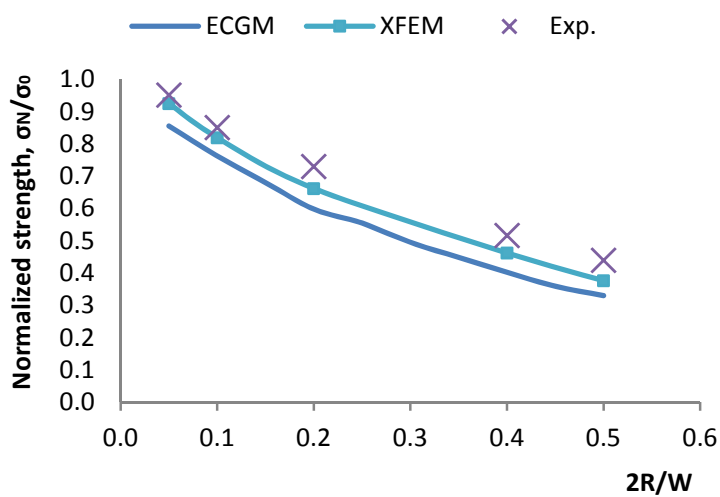

(d) Carbon-Epoxy, $\mathrm{W}=10 \mathrm{~mm}$

Fig. 5. Normalized notched strength plotted as a function of hole size for the laminates tested by Kim et al. [7]. Comparison between experiment, ECGM approach [12] and XFEM results from the current study 


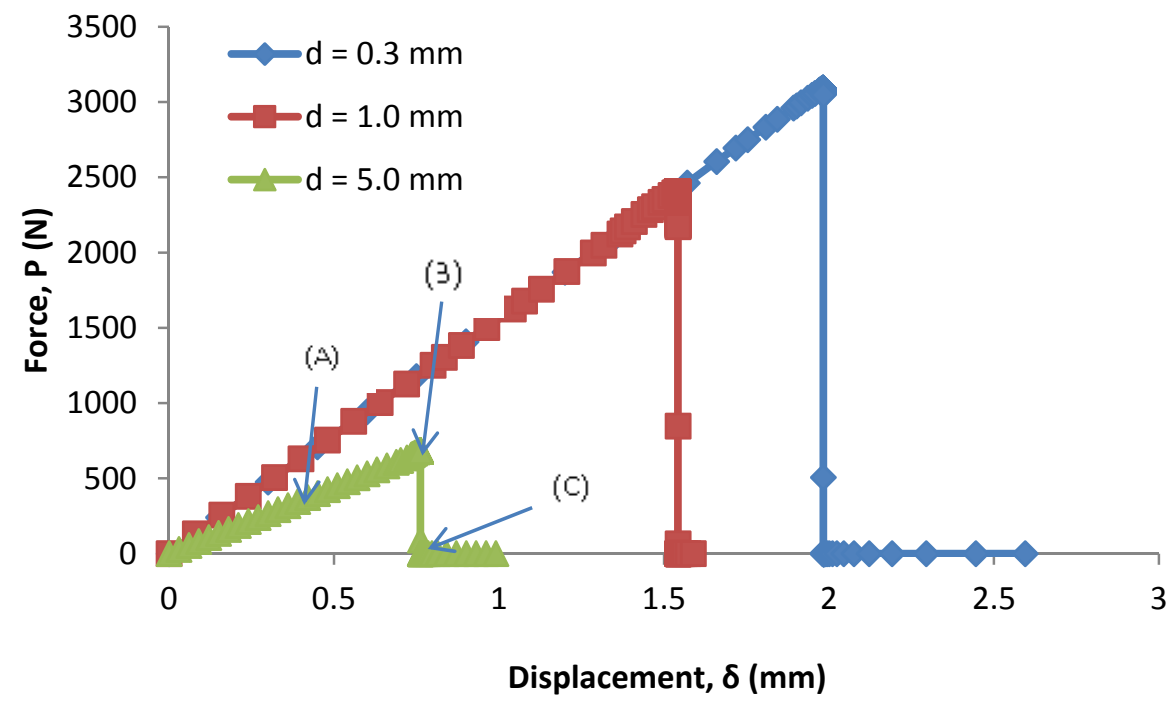

Fig. 6. Typical load-displacement plots resulting from implementing XFEM approach for the laminate reported by Kim et al. [7].
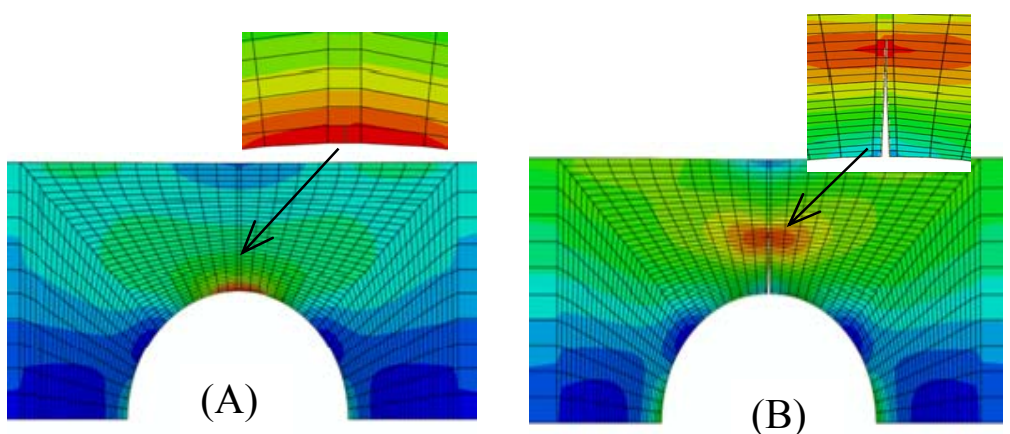

(B)

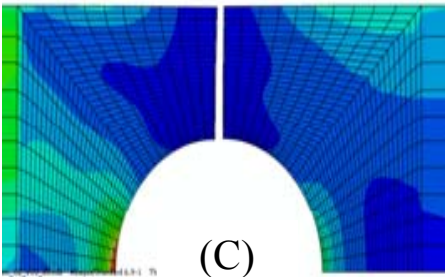

(C)

Fig. 7. Damage plot of crack initiation and crack propagation using XFEM as labelled in Fig. 5 for glass/epoxy ( $w=10 \mathrm{~mm}, \mathrm{~d}=\mathbf{2} \mathrm{mm})$ 


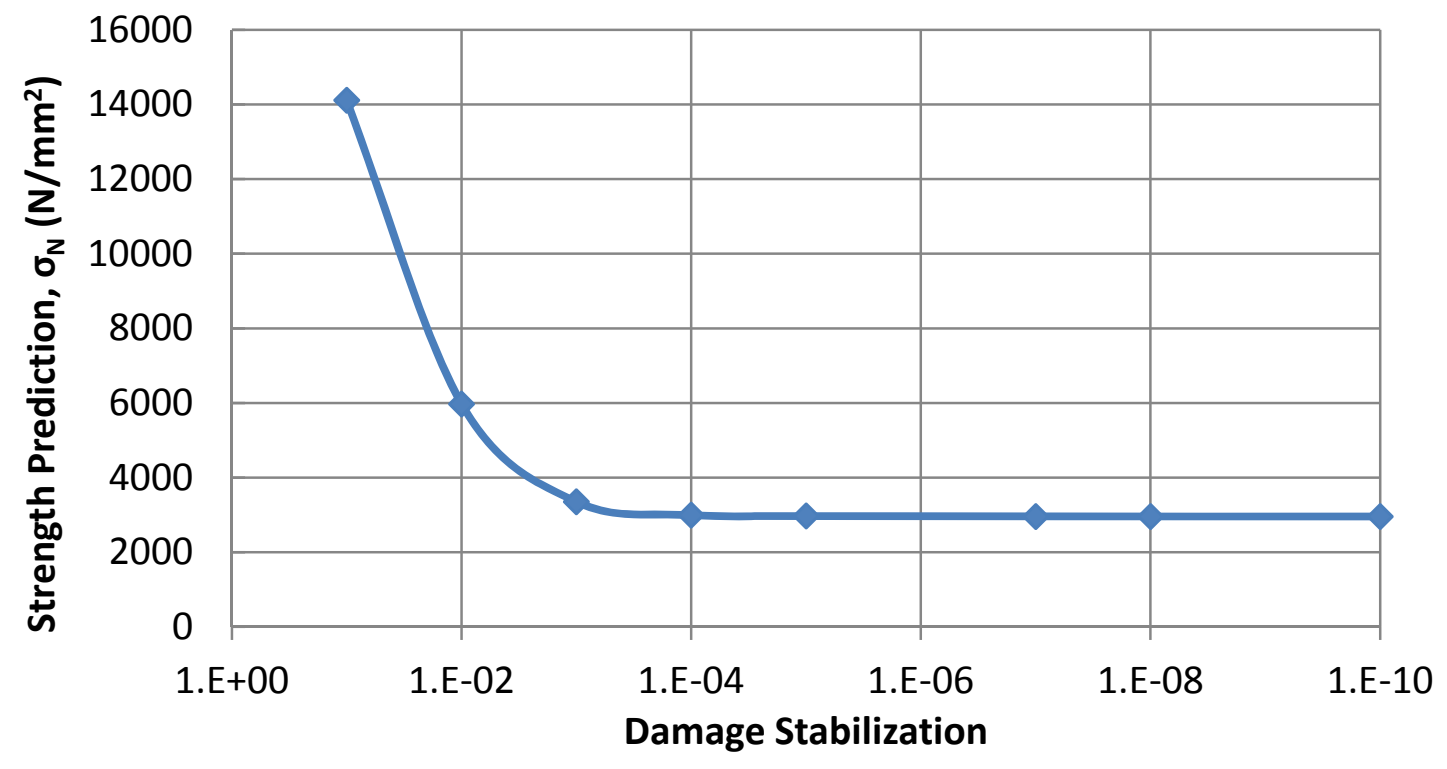

Fig. 8. Notched specimen failure load as a function of damage stabilization coefficient for woven glass-epoxy system (10 mm wide and hole diameter of $0.4 \mathrm{~mm}$ ) following Kim et. al [7].

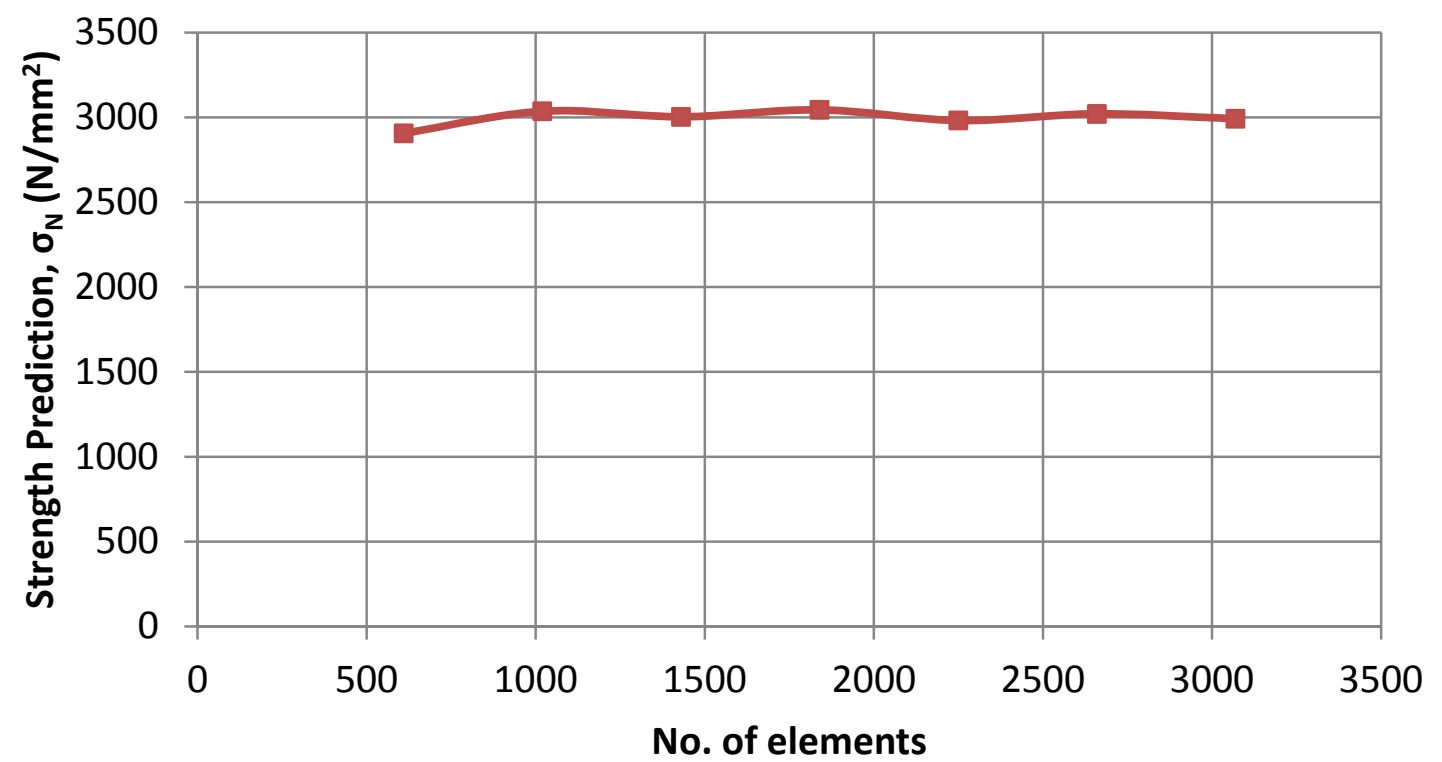

Fig. 9 Notched specimen failure load as a function of number of elements for woven glass-epoxy system (10 $\mathrm{mm}$ wide and hole diameter of $0.4 \mathrm{~mm}$ ) following Kim et. al [7]. 


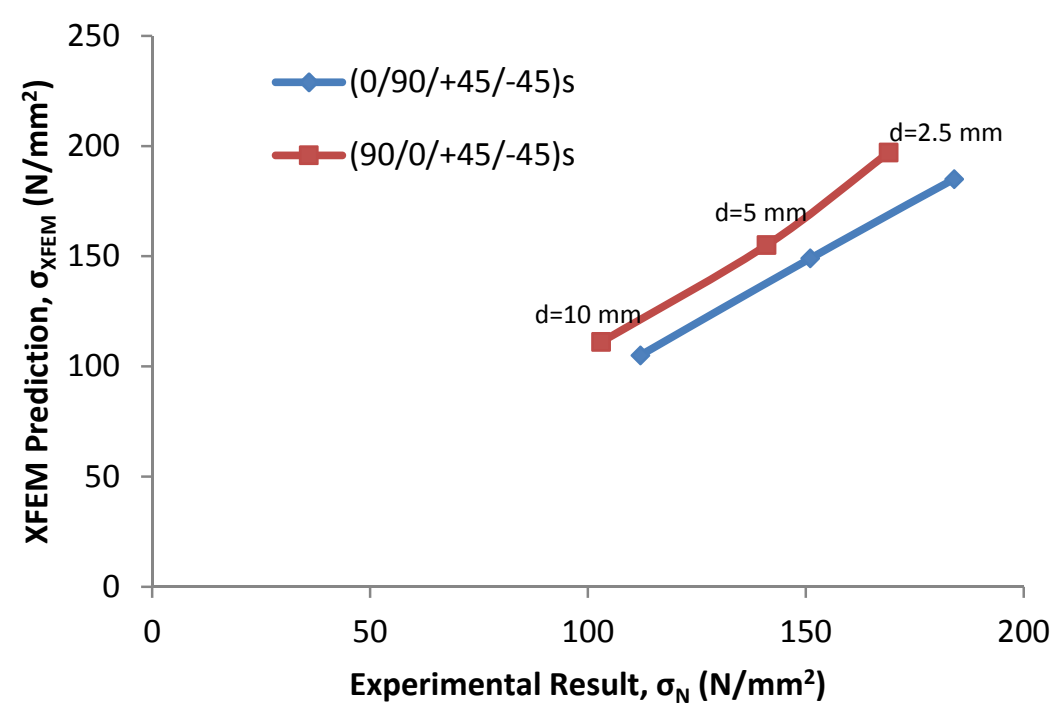

Fig. 10. Comparison of woven GFRP notched strength prediction using XFEM (present work) with experimental data.

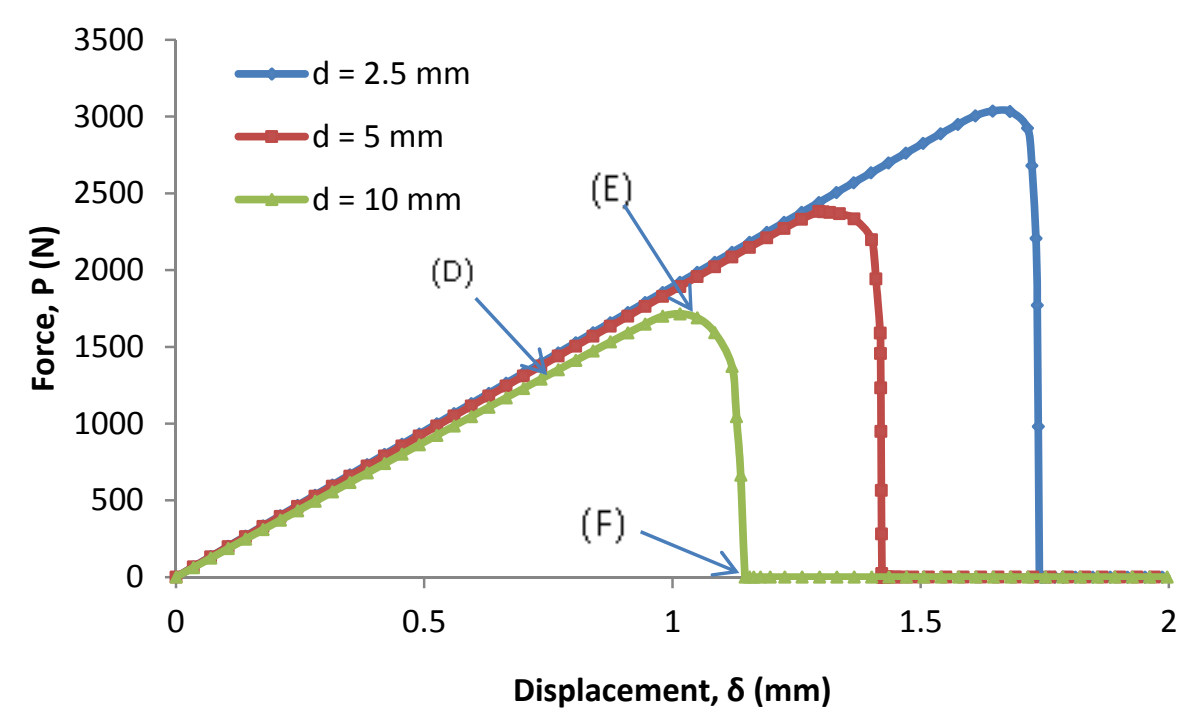

Fig. 11. Typical load-displacement curve from cohesive zone modelling (woven GFRP $\left(0^{\circ} / 90^{\circ} / \pm 45^{\circ}\right)_{\mathrm{s}}$ 

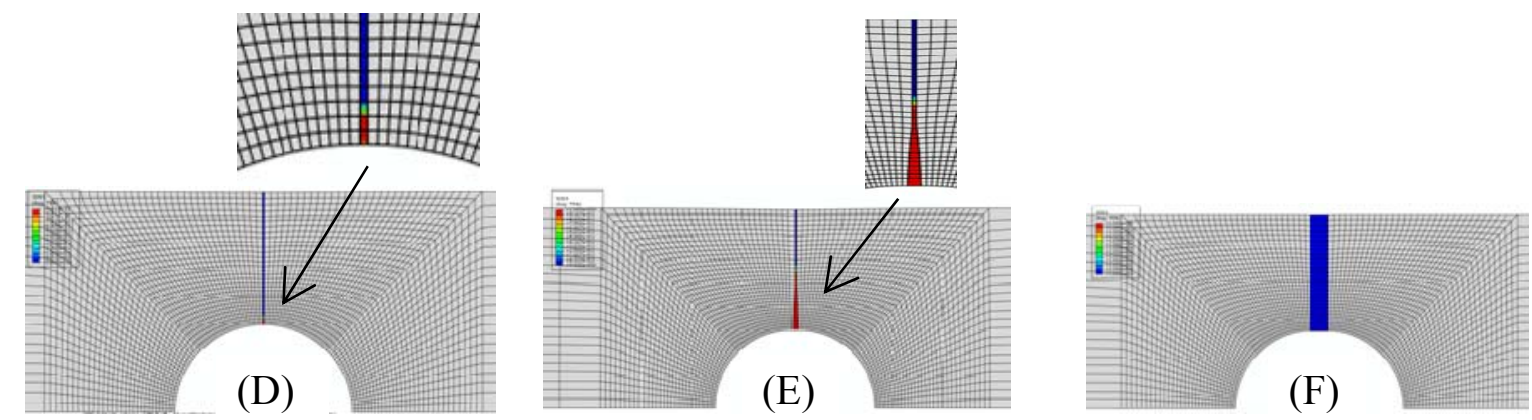

*Note that failure in cohesive zones is denoted as $\mathrm{SDEG}=1$ and given as red colour $(\mathrm{D}, \mathrm{E})$ and blue colour $(\mathrm{F})$.

Fig. 12. Damage plot for cohesive damage modelling using CZM as labelled in Fig. 9 for GFRP plate (d=10 mm).

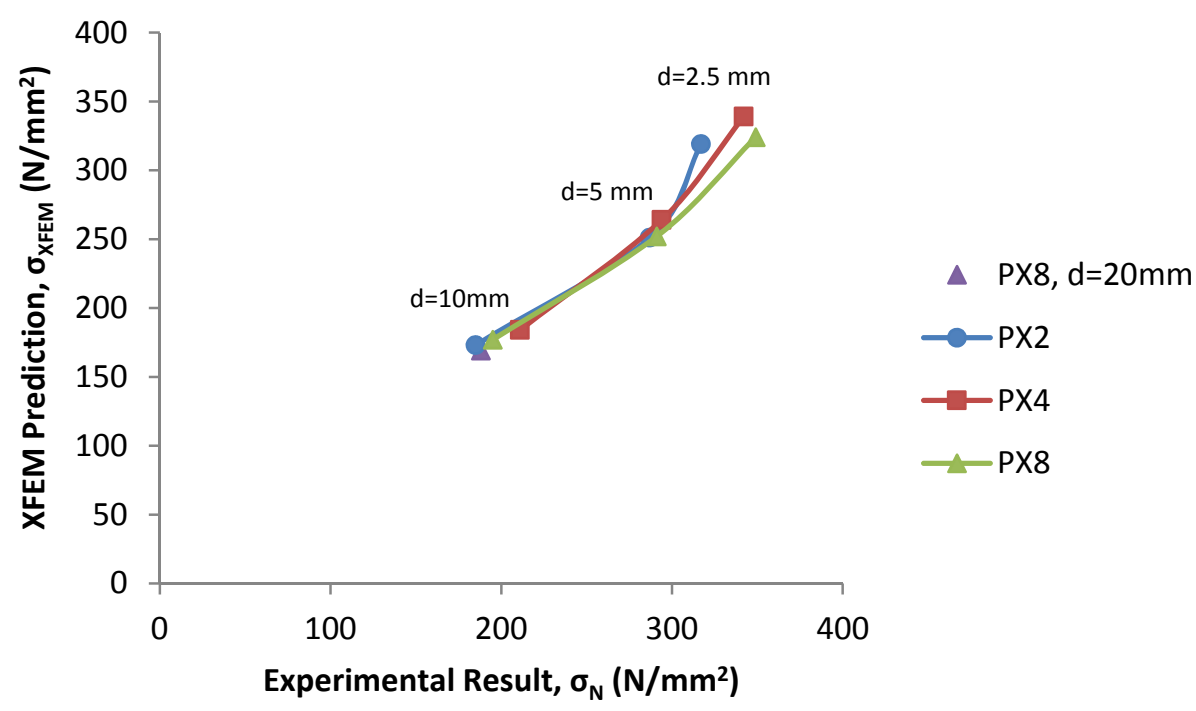

(a) PX series

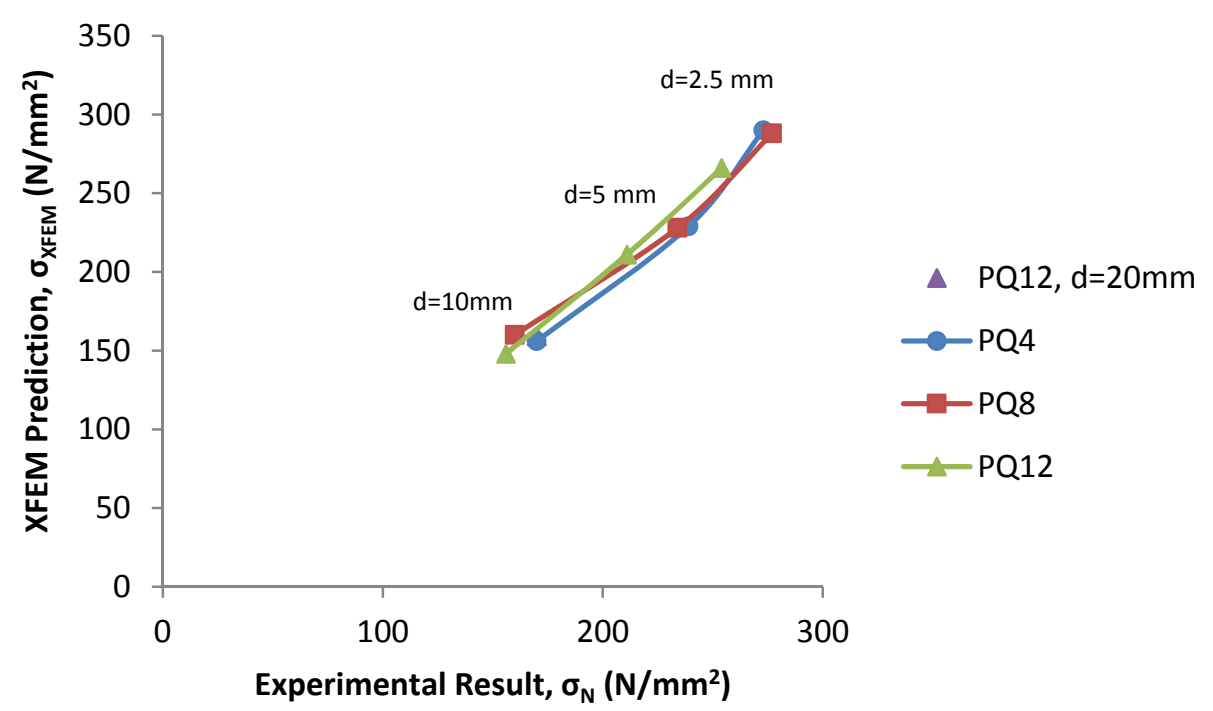

(b) PQ series 


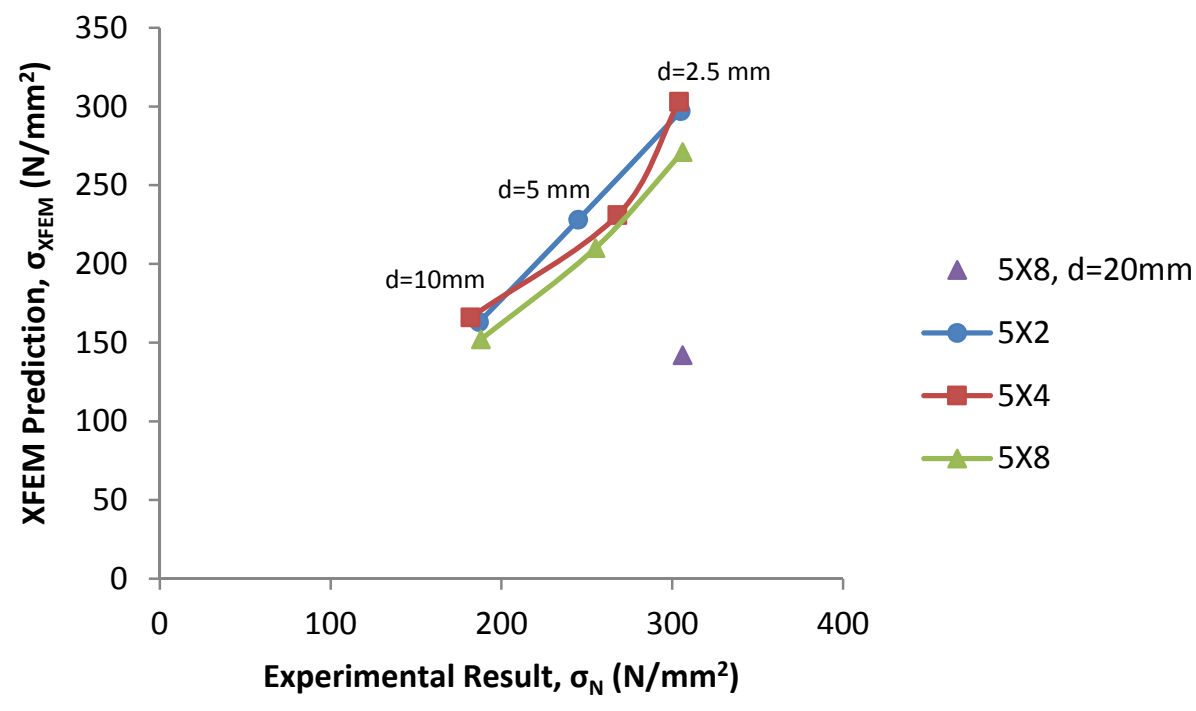

(c) $5 \mathrm{X}$ series

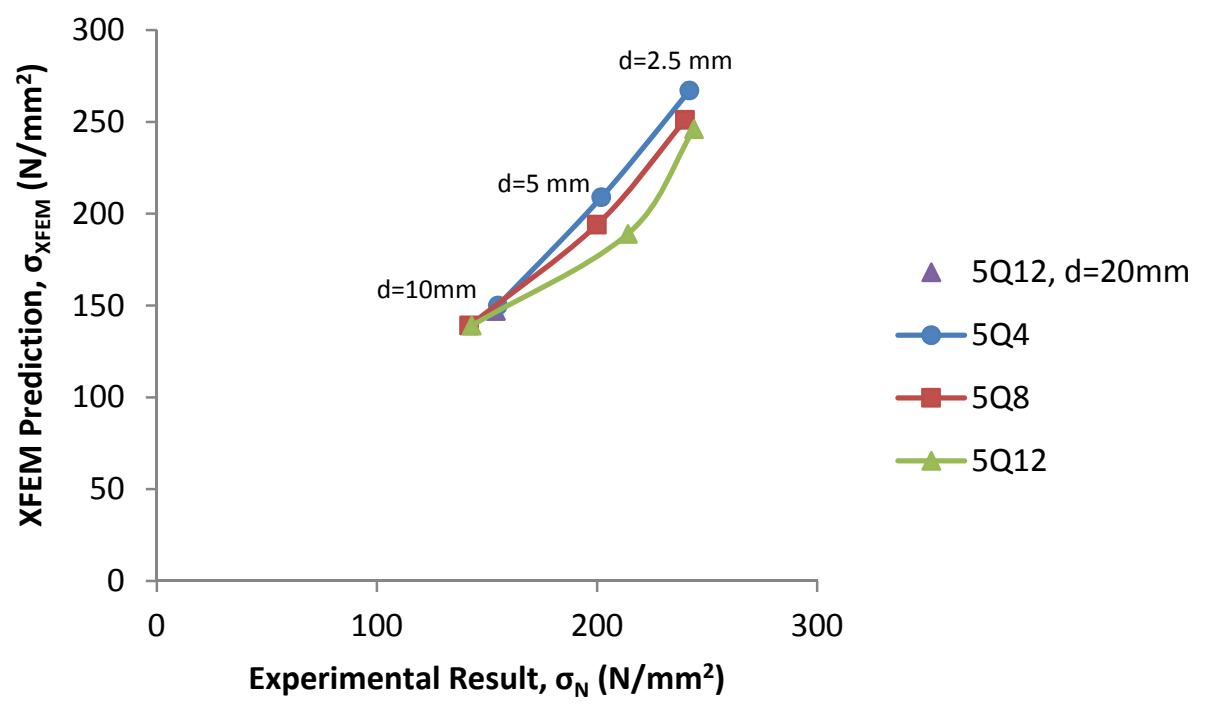

(d) 5Q series

Fig. 13. Comparison of woven CFRP notched strength prediction using XFEM (present work) with experimental data. 
Tables

Table 1: Material properties of woven fabric system conducted by Kim et. al [4]

\begin{tabular}{|c|c|c|c|c|c|c|c|c|c|}
\hline $\begin{array}{l}\text { Materials } \\
\text { type }\end{array}$ & $\begin{array}{l}\text { Thickness, } \\
t(\mathrm{~mm})\end{array}$ & $\begin{array}{l}v_{f} \\
(\%)\end{array}$ & $\begin{array}{l}E_{x x} \\
\text { (GPa) }\end{array}$ & $\begin{array}{l}E_{y y} \\
\text { (GPa) }\end{array}$ & $G_{x y}$ & $v_{x y}$ & $\begin{array}{l}\text { Width } \\
\text { (mm) }\end{array}$ & $\begin{array}{l}\text { Un-notched } \\
\text { strength, } \sigma_{o} \\
\text { (MPa) }\end{array}$ & $\begin{array}{l}\text { Fracture } \\
\text { energy, } \\
G_{c} \\
\left(\mathbf{k J} / \mathbf{m}^{2}\right)\end{array}$ \\
\hline \multirow[t]{2}{*}{ Glass- } & 2.0 & 62 & 23.6 & 23.6 & 4.0 & 0.11 & 10 & 351 & 12.6 \\
\hline & & & & & & & 20 & 319 & 21.2 \\
\hline Epoxy & & & & & & & 40 & 275 & 33.1 \\
\hline \multirow[t]{2}{*}{ Glass- } & 2.3 & 60 & 21.6 & 21.6 & 3.9 & 0.16 & 10 & 309 & 14.9 \\
\hline & & & & & & & 30 & 296 & 17.5 \\
\hline \multirow{2}{*}{ Polyester } & 2.3 & 44.5 & 14.7 & 14.7 & 2.7 & 0.17 & 10 & 218 & 7.50 \\
\hline & & & & & & & 30 & 198 & 8.00 \\
\hline \multirow{2}{*}{ Carbon- } & 1.2 & 60 & 56.7 & 56.7 & 8.7 & 0.22 & 10 & 596 & 30.5 \\
\hline & \multicolumn{9}{|c|}{ Epoxy } \\
\hline \multicolumn{10}{|c|}{$v_{f}=$ fiber volume fraction } \\
\hline \multicolumn{10}{|c|}{$E_{x x}=$ longitudinal Young's modulus } \\
\hline \multicolumn{10}{|c|}{$E_{y y}=$ transverse Young's modulus } \\
\hline \multicolumn{10}{|c|}{$v_{x y}=$ Poisson's ratio } \\
\hline$t=$ laminat & hess & & & & & & & & \\
\hline
\end{tabular}

Table 2: Material properties for woven GFRP from Belmonte et. al [6]

\begin{tabular}{|c|c|c|c|c|c|c|c|}
\hline $\begin{array}{l}\text { Stacking } \\
\text { sequence }\end{array}$ & $\begin{array}{c}t \\
(\mathrm{~mm})\end{array}$ & $\begin{array}{c}E_{x} \\
(\mathrm{GPa})\end{array}$ & $\begin{array}{c}E_{y} \\
\text { (GPa) }\end{array}$ & $\mathbf{V}_{\mathbf{x y}}$ & $\begin{array}{c}G x y \\
(G P a)\end{array}$ & $\begin{array}{c}\sigma o \\
\text { (MPa) }\end{array}$ & $\begin{array}{r}G_{c} \\
\left(\mathbf{k J} / \mathbf{m}^{2}\right)\end{array}$ \\
\hline$\left(0^{\circ} / 90^{\circ} / \pm 45^{\circ}\right)_{\mathrm{s}}$ & 1.25 & 15.9 & 15.9 & 0.3 & 6.10 & 291 & 20.3 \\
\hline$\left(90^{\circ} / 0^{\circ} / \pm 45^{\circ}\right)_{\mathrm{s}}$ & 1.25 & 16.0 & 16.0 & 0.3 & 6.10 & 291 & 20.3 \\
\hline
\end{tabular}

*The unnotched strength and toughness values for the $\left(90^{\circ} / 0^{\circ} / \pm 45^{\circ}\right)_{\mathrm{S}}$ stacking sequence was assumed to be the same as for the $\left(90^{\circ} / 0^{\circ} / \pm 45^{\circ}\right)_{\mathrm{s}}$ stacking sequence

Table 3: Material properties all woven CFRP from Belmonte et. al [7]

\begin{tabular}{|c|c|c|c|c|c|c|c|c|}
\hline Series & $\begin{array}{c}\text { Laminate } \\
\text { code }\end{array}$ & $\begin{array}{c}t \\
(\mathrm{~mm})\end{array}$ & $\begin{array}{c}E_{x} \\
(\mathrm{GPa})\end{array}$ & $\begin{array}{c}E_{y} \\
\text { (GPa) }\end{array}$ & $v_{x y}$ & $\begin{array}{c}G x y \\
\text { (GPa) }\end{array}$ & $\begin{array}{c}\sigma_{o} \\
\text { (MPa) }\end{array}$ & $\begin{array}{r}G_{c} \\
\left(\mathbf{k J} / \mathbf{m}^{2}\right)\end{array}$ \\
\hline weave & $\mathrm{PX} 2$ & 0.51 & 50.4 & 50.4 & 0.103 & 4.42 & 481 & 26.0 \\
\hline \multirow[t]{2}{*}{ cross-ply $(P X)$} & PX4 & 1.03 & 51.4 & 51.4 & 0.092 & 4.42 & 527 & 27.7 \\
\hline & PX8 & 2.03 & 53.1 & 53.1 & 0.083 & 4.42 & 538 & 22.7 \\
\hline weave & PQ4 & 1.02 & 37.2 & 37.2 & 0.353 & 13.8 & 390 & 21.6 \\
\hline quasi-isotropic & PQ8 & 2.03 & 36.8 & 36.8 & 0.328 & 13.9 & 428 & 17.9 \\
\hline$(P Q)$ & PQ12 & 3.17 & 35.2 & 35.2 & 0.297 & 13.6 & 372 & 18.3 \\
\hline
\end{tabular}




\begin{tabular}{|c|c|c|c|c|c|c|c|c|}
\hline 5 Harness satin & $5 \times 2$ & 0.81 & 45.1 & 45.1 & 0.077 & 3.78 & 419 & 28.8 \\
\hline \multirow[t]{2}{*}{ cross-ply $(5 X)$} & $5 \times 4$ & 1.60 & 47.0 & 47.0 & 0.062 & 3.78 & 535 & 20.0 \\
\hline & $5 \times 8$ & 3.15 & 47.4 & 47.4 & 0.053 & 3.78 & 456 & 17.6 \\
\hline weave & $5 \mathrm{Q} 4$ & 1.53 & 34.1 & 34.1 & 0.296 & 13.2 & 375 & 19.2 \\
\hline quasi-isotropic & $5 \mathrm{Q} 8$ & 3.17 & 33.5 & 33.5 & 0.320 & 12.7 & 347 & 16.8 \\
\hline$(5 Q)$ & $5 \mathrm{Q} 12$ & 4.59 & 34.8 & 34.8 & 0.322 & 13.2 & 370 & 12.9 \\
\hline
\end{tabular}

